\title{
The Impact of Amharic Linguistic Interference on Tigrinya as Medium of Education: The Case of Alamata Primary Schools
}

\author{
Niguss Weldezgu \\ Arba Minch University, College of Social Sciences and Humanities, \\ Department of English Language and Literature
}

\begin{abstract}
This paper deals with the impact of Amharic (neighbor language) linguistic interferences on the Tigrinya variety used as medium of instruction, particularly in Alamata primary schools, south Tigray in north Ethiopia. The study is mainly concerned with the description and analysis of the linguistic interferences of Amharic into the Tigrinya variety used as medium of instruction. It is also aimed at pointing out the impacts of the linguistic on the medium of instruction and at suggesting some measures which can possibly solve or reduce the impacts. In order to achieve these objectives, a questionnaire, an interview, a writing test and personal classroom observations have been used as the main data collection instruments. Six primary schools have been selected using random and purposive sampling method. Grade seven students and their Tigrinya teachers have also been selected as sample subjects of the study using random sampling technique. The data, therefore, have been collected through the aforementioned methods from these subjects during schooling time. Both quantitative and descriptive methods have been used in an integrated way to analyze the data. The data have revealed that the influence of Amharic on the Tigrinya variety used as MOI is high at all linguistic levels (phonology, morphology, syntax and lexical), and it brings about negative effect in classroom communication. Moreover, it has also been found that there are innovations of linguistic elements.
\end{abstract}

DOI: $10.7176 / \mathrm{JLLL} / 66-02$

Publication date:March $31^{\text {st }} 2020$

\section{Introduction}

\subsection{Background of the study}

Language enables human beings to live together in society, to develop and exchange ideas and to plan for the future; it is a critical means of gaining access to important knowledge and skills, and it is a tool for all aspects of human civilization and indispensable to every human activity (Ager, 1996:1). Fentahun (1999:9), states that "language-spoken, heard, written and read is part of everything." Therefore, as language is part of everything, it also plays a significant role in the realm of education which is the key to all human civilization.

As to the best understanding of the researcher, language and education are not separable, especially in the overall activities of the instructional process. The role of language in the instructional process is very critical because it represents a people's theory of reality; it explains, interprets, constructs and reproduces that reality (Smitherman, 1998:58). As Spolsky (1972:3) and Thomas (1990:1-2) noted, learning in school depends on an interaction to interaction of the pupil with his/her teachers, books and peers, and all these interactions are mediated by language. Most of his/her teaching takes place through language, and most of his/her learning depends on a pupil's ability to understand what his/her teacher says and what is in his/her text books. That is, success in learning depends basically on the ability of the learners to understand the teaching-learning process and to express themselves in the language that is used for learning. Hence, for Thomas and Spolsky, students who lack sufficient language skills not only fail to express ideas in the language but they also fail in the other subject areas as well.

Generally, language is an essential means of interaction, explanation, sharing ideas and mutual understanding in the instructional process. Numerous studies have shown that there is a positive correlation between the medium of instruction and success at school. Thus the choice of medium of instruction in societies with plurality of languages is fundamental for the teaching - learning process. The question then, according to Annamalai (2003) "is which language will serve as the effective medium of instruction." Effectiveness, for Annamalai, is not about the quality of language to be used but is about the quality of education that is aimed at, whether it is interactive, creative and critical.

\subsection{Statement of the problem}

There are a number of researches done by different researchers in different times on the dialectal variations of the Tigrinya language. Particularly, three researches "The Phonology of Rayya Dialect of Tigrinya" by Mohammed Siraj (1983) and The Role of Media in Creating Standard Dialect in the Case of Ofla Woreda by Yikune-Amlak Mezgebe (2000) have been conducted on what and how the dialect of Rayya varies from the other dialects of Tigrinya so far. However, any one of them did not attempt to touch the impact of the Amharic linguistic interference on the implementation of the Tigrinya variety used as medium of instruction in the Southern Zone, particularly in the primary schools of the Alamata woreda, where the interference of Amharic is high. This study, 
therefore, has been conducted to fill this gap.

Although there have not been witnessed as such great linguistic disparities among all the Tigrinya dialect speakers, the Tigrinya varieties spoken in Wejerat and Raya show a linguistic deviation than the other varieties of the language (see Tsehaye Kiros, 2009; Moges Ali, 1993). This is mainly due to the fact that the dialect spoken in Wajerat is nearest to Ge'ez (Tsehaye Kiros, 2009:9) and the dialect spoken in Alamata Woreda is highly influenced by the contact with the neighboring language called Amharic (Moges Ali, 1993: 38). Moges states that most of the Alamata people are always observed facing difficulties to speak and understand the dialects spoken in the other parts of the Tigray Region.

Therefore, the influence of Amharic linguistic on Tigrinya has motivated the researcher to look into it and its impact on the actual classroom instructional processes in the case of Alamata primary schools. To this end, the researcher has raised the following research questions to be answered throughout the study.

1. What are the linguistic influences of Amharic on Tigrinya?

2. What is the impact of the influence of Amharic linguistics on the medium of instruction and on the academic achievement of the students in Alamata primary schools?

3. What measures have to be taken to solve/reduce the problems?

\subsection{Objectives of the study}

\subsubsection{General objective}

The overall objective of this study is to survey impacts of the Amharic linguistic interferences in the implementation of the Tigrinya variety used as medium of instruction in the Alamata primary schools.

\subsubsection{Specific objectives}

The specific objectives of under taking this study are:

$>$ to see the linguistic interferences of Amharic in the Tigrinya variety used as medium of instruction, particularly in Alamata primary schools;

$>$ to critically analyze the impact of the Amharic linguistic interferences in the students particularly in the case of Alamata primary schools;

$>$ to offer (recommend) some strategies that can possibly overcome or reduce the problem.

\subsection{Significances of the study}

This study may:

\# serve as a reference and pave the way for other researchers who are interested in conducting study on this or other similar areas.

\& serve as a reference material for language planners in Tigray and decision makers, Tigrinya curriculum designers, teachers of Alamata primary schools and other concerned bodies for any required action.

give feedback to Tigray Regional Education Bureau (TREB) so that it may be able to re-consider the Alamata dialect in the curriculum.

\subsection{Scope and delimitation of the study}

Had it been possible to carry out the study at the Zone level, the result obtained would have been representative of the southern zone as a whole. However, the researcher has found that it would be very unmanageable to widen the study to include all the primary schools of the southern zone of Tigray. Hence, in order to make the study manageable, the researcher has limited the study only to investigate how the interferences of Amharic linguistics into the Tigrinya variety used as medium of instruction could bring about negative impact on the classroom instructional processes specifically in Alamata primary schools; it was also quite difficult to conduct the study in all the 61 primary schools of Alamata because of the financial and time constraints. Therefore, the researcher has intended to select six primary schools: three from the Alamata town and three from the rural areas (RayyaAlamata), which are believed to represent the whole primary schools of the woreda.

\section{Research methodology}

This chapter deals with the presentation of methods employed in the data collection, data analysis and interpretation of the paper. Questionnaire, interview, written tests and classroom observations have been employed in the data collection. This is to cross check the data collected via multiple methods of data collection. This only can be assured using multi method approach of data collection; as Teshome (1998:46) argues, multiple methods should be used in every investigation as a rule because each method reveals different aspects of empirical reality. The author explains that triangulating such methods as interviews, observations, questionnaires, and document analysis constructs, checks and balances to a particular study.

In addition to this, Brewer and Hunter (1989) and Patton (1987) discuss that there are strengths and weaknesses to any single data collection instrument; therefore, using multiple methods of data gathering 
instruments will help to cross-check the validity of data in any research. Teshome (1998:46) also argues that using more than one data collection approach permits the study to combine the strengths and correct some of the deficiencies of any source of data. Furthermore, Wellington (1996:17) states that a mixture of data collection methods can often be adapted even in a single small-scale study. Wellington added that both qualitative and quantitative methods can exist side-by-side in data analysis of an enquiry. Therefore, by taking the necessity of all the information suggested by the above authors into account, the researcher in this study was persuaded to use qualitative and quantitative data analysis approach for the data collected through the aforementioned methods of data collection. In this study, therefore, questionnaire, interview, observation and writing test were employed as main data gathering instruments. How these tools were employed will be briefly discussed in section 3.2 below.

\subsection{Subjects of the study and sampling technique}

The targeted populations of this study were the students of the Alamata primary schools and their Tigrinya teachers. These children were identified as the subjects of the study due to the fact that they have been observed speaking a Tigrinya variety, which is highly influenced by Amharic (Moges, 1993: 38-40). The total number of primary schools in Alamata Woreda is 61. From this number of primary schools, eight of them are found within the Alamata town and its surroundings; the remaining 53 primary schools are found in the rural areas (Rayya-Alamata) of the woreda

The researcher randomly selected three (Mibraq, Bruh-Tesfa and Edget-Fana primary schools) from among the eight primary schools found in the Alamata town. However, the researcher was forced to select three primary schools from the rural areas (Rayya Alamata) (Selen-Weha, Wajja and Tumuga) purposefully (using purposive sampling method) by taking time constraints, access of transportation, meal and accommodation services and other similar reasons into account.

The researcher has also randomly selected only one grade level i.e. grade seven from each of the sample primary schools of the woreda for this study. There are 20 grade seven sections and a total of 900 students in all the six sample primary schools. Of the 20 grade seven sections, eight (8) sections have been selected randomly as the sample of this study. In the same fashion, the researcher has randomly selected 168 students, 21 from each of the 8 sample sections to fill questionnaire. Of this 168 sample students, $88(55 \%)$ are male while $80(45 \%)$ are female. In addition, 96 (55 male and 41 female) students have been selected randomly from the total of 168 sample grade seven students for writing test. Furthermore, all the Tigrinya teachers ( 8 in number) of the sample sections have been taken for interview. Of the eight (8) Tigrinya teachers, $5(62.5 \%)$ are male while $3(37.5 \%)$ are female (see subjects of the study in appendix-I). The primary data, therefore, were collected from the above sample subjects of the study.

\subsection{Tools of data collection}

The raw data were collected from the sample subjects of the Alamata primary schools through questionnaire, interview, writing test, and personal classroom observations. The data collection processes were facilitated and gathered by the researcher himself during schooling time. In other words, the researcher spent his time in the study area for the purpose of data collection.

\subsubsection{Questionnaires}

To collect the necessary data, questionnaire was employed as one means of data collection tool. A questionnaire, having both close and open ended questions was prepared and distributed to 168 ( 88 male and 80 female) sample grade seven students of the sample Alamata primary schools. The questionnaire includes questions that require information about the students to get background information about how the influence of Amharic linguistics on the Tigrinya variety used as medium of instruction is high and information about how much the interference of Amharic linguistics into the medium of instruction could affect the classroom communication. This method was used mainly in order to get primary information from the subject students about their difficulties in classroom communication. Since the subject students were grade seven students, the questionnaire was first prepared in English and then it was translated into Tigrinya by the researcher himself and then evaluated by colleagues who are Tigrinya teachers.

\subsubsection{Interview}

The other type of instrument used to collect the raw data was an interview. The researcher conducted an interview to Tigrinya teachers. The interview used guided questions in order to make the interviewees stick to the required information. According to Borg and Gall (1989) and Kvale (1996), in an interview situation, an interview guide helps to indicate the outlines of the topics to be covered. In addition, Chernet (1999:39) argues that interview guidelines also help the interviewer to concentrate or focus on what to say at the opening and closing of the interviews. So for this purpose, the researcher constructed and used interview guidelines in this study. As a result of the necessity to frame interview questions in language that ensures effective communication between the interviewees and the interviewer (researcher), all the interviews were made using Tigrinya language in which both the interviewees and the researcher can communicate sufficiently. Thus the interview guidelines were first 
prepared in English and then translated into Tigrinya; after the interview guidelines were translated into Tigrinya, they were evaluated by colleagues who have Tigrinya background, and certain modifications were made according to their suggestions. All the interviews were recorded using a tape recorder. However, according to Wellington (1996:34), the use of mechanical aids such as audio recorders, may be seen as obtrusive in some situations. Respondents may not wish their views to be recorded on tape. In order to take care of this problem, therefore, the researcher briefly informed the interviewees about his background and the general purpose of the interview and secured their permission. This means that the respondents were clearly informed about the general objective of the research so that participating in the research would not threaten their social welfare.

The contents of the questionnaire which was administered to the sample grade seven students of Alamata primary schools and the contents of the interview which was conducted to the Tigrinya teachers of the above sample grade level were not entirely different types; some of the items were intentionally made similar in order to cross-check the feedback from both of the two groups of respondents.

\subsubsection{Observation}

According to Trochim, B. (1999), observation refers to a type of study in which individuals are observed and certain outcomes are measured. According to the author, observation allows the researcher to study people in their "natural setting" without their behavior being influenced by the presence of a researcher, and observational data usually consists of detailed information about a particular group or situation. This kind of data can "fill out" and provide a deeper and richer understanding about a larger number of people. Trochim states that some methods only allow for the study of one individual at a time; observation, however, enables the researcher to study groups of people together, that is, it allows for the study of interaction between the members of a group, and some times, observation is the only way of finding out about a certain study at school.

The researcher in this study, therefore, conducted a critical classroom observation using observational check list in order to see if there have been interference of Amharic into the language of instruction (Tigrinya) during the actual classroom teaching learning process. The main emphasis of the researcher, here, was to critically observe the interferences of linguistic aspects such as, phonology, grammar (morphology and syntax) and lexicon of Amharic into the medium of instruction made by the sample students, and also to notice if confusion and/or communication gap between the sample grade seven students of Alamata primary schools and their Tigrinya teachers takes place as a result of the Amharic interference problems into the medium of instruction in the actual classroom oral interaction. Here, the researcher tried his best to write down any linguistic interference of Amharic which the subject students made into the language of instruction in the actual classroom teaching-learning process during Tigrinya sessions as much as possible.

\subsubsection{Writing test}

The other method of data collection instrument used in this study was a writing test. The main purpose why the researcher preferred to employ this method, was in order to see if the sample grade seven students of Alamata primary schools would show any interference of linguistic items from the phonology, grammar (morphology and syntax) and lexicology of Amharic into the medium of instruction in their written language and then to see if such interferences bring about any distortion in meaning. The researcher, therefore, randomly selected 96 (55 male and 41 female) grade seven students from the total 168 sample students for the writing test. These students were required to write a paragraph of their own, using at least 100 words in the medium of instruction.

\subsection{Methods of data analysis}

The researcher has employed both the quantitative and qualitative methods. The quantitative method has been used in order to analyze numerical data. The qualitative method, on the other hand, is employed so as to describe nonnumerical data particularly linguistic data in such aspects as phonology (pronunciation), grammar (morphology and syntax) and vocabulary (lexicon) in the written form. Descriptive analysis and interpretation is also used. And in the output, results and discussions are organized and presented in narratives and tables. Finally, the researcher has interpreted and described the data based on the results of the analysis. For convenience, the researcher has tried to integrate and treat together all the date obtained through the different data gathering instruments in the analysis and discussion parts. In general, the research is based on qualitative data and on basic descriptive statics of the sample.

\section{Data analysis and discussions}

This section undertakes the descriptions and discussions of the result of the research. Document analysis, questionnaire, interview, writing test and personal classroom observations were used as the main means of data collection instruments. A total of 168 copies of the questionnaire were distributed for 88 male and 80 female sample grade seven students of the Alamata primary schools. Out of these questionnaires, $160(95.24 \%)$ were returned to the researcher. Moreover, an interview with 8 ( 5 male and 3 female) grade seven Tigrinya teachers was conducted. The writing test was administered for 96 (55 male and 41 female) grade seven students of the sample primary schools. These students were required to write a paragraph of their own, using at least 100 words. In 
addition to these methods of data collection, a critical classroom observation was conducted using observational check list. The data obtained by all the above instruments are described, analyzed and discussed in an integrated way in order to avoid redundancy. Tables, numerical and narrative expressions are used for the description and analysis.

Amanuel (1988: 15-20), Mohammad (1983:1), Teklehaymanot (2000:167-169) and Daniel Teklu (2000:220221) discuss that Amharic has a significant influence on Tigrinya. Meaza (1983) also pointed out that there is a close contact and problem of interference between Amharic and Tigrinya as follows.

The two languages (Amharic and Tigrinya) are in close contact in every aspect, geographically and linguistically. One knowing the close contact and similarity might not believe that there is a problem of interference between these languages. But whether the reasons are the slight difference, the similarity or any other, there is a problem of interference (Meaza, 1983:2).

The field work of this research has shown that in the sample schools of the Alamata Town, particularly in "Bruh-Tesfa" and "Edget-Fana" primary schools, phonological interferences of Amharic into medium of instruction were witnessed. During classroom observations some individuals were noticed using Amharic phonemes in the place of certain Tigrinya words during Tigrinya sessions. The interference of such Amharic phonemes sometimes brings about a total change in meaning, and sometimes they involve Amharic words which do not have any meaning in the medium of instruction. The researcher then tried to show some examples how such sound interferences bring about change in meaning or how they create words which do not have any sense in the medium of instruction in the table below.

\begin{tabular}{|c|c|c|c|c|c|c|}
\hline \multicolumn{2}{|c|}{ Basic words } & Pron in $\mathrm{MOI}^{1}$ & Meaning in MOI & Students' & Meaning in MOI & Sound \\
\hline $\mathrm{a}$ & Sibyet & Sibyet & 'development' & Pibyet & 'being unwilling' & \multirow{9}{*}{$ৎ \Rightarrow ?$} \\
\hline $\mathrm{b}$ & Gibud & Gibud & 'crazy' & Pibud & --------------- & \\
\hline $\mathrm{c}$ & Sallamay & Sallamay & 'one who hits a target' & Pallamay & 'one who waves' & \\
\hline $\mathrm{d}$ & Sillama & Silama & 'purpose' & Pilama & --------- & \\
\hline $\mathrm{e}$ & Saddäy & Saddäy & 'my country' & Paddäy & 'my mother' & \\
\hline $\mathrm{f}$ & S'aSri & s'aSri & 'effort' & s'a?ri & ---------- & \\
\hline $\mathrm{g}$ & SiSat & siSat & 'clock' & si?at & ----------- & \\
\hline $\mathrm{h}$ & saStrri & saqtiri & 'grass' & saPirri & ------------- & \\
\hline $\mathrm{i}$ & maৎrä & $m a \Upsilon r a ̈$ & 'equal' & maPrä & 'some to be picked up' & \\
\hline $\mathrm{j}$ & Harisu & $\hbar a r i s u$ & he ploughed & Harisu & 'he slept' & \multirow{3}{*}{$\hbar \Rightarrow h$} \\
\hline $\mathrm{k}$ & ћirum & hirum & 'for bidden' & hirum & ' hit (passive verb)' & \\
\hline 1 & hibu?; & hibu? & ' hidden' & hibu? & ---------- & \\
\hline
\end{tabular}

Table 1: Sounds and meanings changed due to Amharic influence

As we can see in the above data, there is a total meaning change as well as meaning loss due to sound variations between the pharyngeal [S] and the glottal [P] in the first case and between the pharyngeal [ $\hbar]$ and the glottal $[\mathrm{h}]$ in the second case in each of the words between the pronunciation of the medium of instruction and what the students actually pronounce. For instance, we can see a variation between the phoneme $/ \mathrm{S} /$ which in the MOI is pharyngeal, fricative and voiced [Y] while it is glottal, stop and voiceless [?] in the students' pronunciation.

These pharyngeal consonants are not found in Amharic, and are difficult for Amharic speakers to pronounce them as do Tigrinya native speakers. They, for instance, pronounce the pharyngeal [S] instead as the glottal [?]. In this case, there is again meaning change that results from the variation.

The same is true with the pharyngeal, fricative voiceless [ $\hbar]$. The [ $\hbar]$ does not exist in Amharic, and it is again common to observe Amharic speakers pronouncing it as the glottal [h]. This also results in a meaning change as one can witness it in the words of the above data.

According to the data, some student subjects of this study showed the same phonological changes in their pronunciation of the basic words that have these pharyngeal consonants as shown in the table above. For instance, the replacement of the pharyngeal [G] by the glottal [?] in the pronunciation of the students as one can clearly see in the above data brings a total lexical (meaning) change. For example, the pharyngeal [G] in the MOI words $m a \varsigma^{\prime} \ddot{a}$ "equal", Galäma "purpose" and Gibyät "development" is changed into the glottal [?] as in ma?rä "picking up", Paläma "waving" and Pibyät "being unwilling".

Besides, the replacement of the pharyngeal [ $\hbar]$ by the glottal [h] also causes total lexical change, which brings communication gap between the teachers and the subject students during classroom sessions. For example, the pronunciation of $[\hbar]$ as in the word [sira $]$ in the MOI has the meaning of 'work' whereas the pronunciation of [h] in the word [sirah] pronounced by the subject students does not have any meaning in the MOI. Moreover, in the MOI, the pronunciation of [ $\hbar]$ in the word $\hbar a b b o$ "motive", is replaced by $[\mathrm{h}]$ in the pronunciation of the students to become [habbo] "give him" in the MOI. The [ $\hbar$ ] in the word ziћarämo has the meaning of "that is forbidden for

\footnotetext{
${ }^{1}$ Pron in MOI [pronunciation in the medium of instruction]
} 
someone to have or to own something" in the MOI, but the meaning is changed in the students pronunciation due to the fact that they pronounce the $[\hbar]$ sound as $[\mathrm{h}]$ as in the word diharämo which in the MOI means "one (3SGM) who hit him". Moreover, harisu in the MOI means "he ploughed", but it is pronounced as [harisu] by the subject students, and it gives the meaning of "he slept" in the MOI.

In the data obtained by the writing test, many words which have similarity with some Amharic words were identified. For instance, the words sinday, t'iray, käfti and bix'addämay of the subject students have similarity with the Amharic words siniddiye "wheat" t'irre "any crop", käbt "cattle" and bäk'äddäm "in the previous time" respectively. In addition, some Amharic borrowed words were found in the written test of the subject students; for example, the words Pandäňňa "first" gäläba "hay", Piwk'ät "knowledge", mäbt "right", $t$ 'tyyak'e "question" and the like are borrowed from Amharic. This shows that the interference of Amharic in the Tigrinya variety used as medium of instruction (MOI) is very high and brings a communication barrier in the actual classroom teaching learning processes, particularly in the Alamata primary schools.

The grade seven students of the sample primary schools of Alamata were also noticed when they use some of the words given in the above data in their oral classroom interaction. So from such lexical interferences of Amharic into the Tigrinya variety used as MOI by the students, one can conclude that there has been communication gap between/among the students and the Tigrinya teachers in the actual classroom interactions, mainly due to meaning variation.

Many of the students have been noticed using Amharic words both in the oral and written forms during Tigrinya sessions. For, instance, the students were observed using Amharic words such as $t$ 'tyyak'e "question" lämissale "for example", Piwk'ät "knowledge" and the like instead of the corresponding Tigrinya words, hitto, $n \dot{t}$ Pabinnät, filt 't' $\mathrm{a} t$ and the like respectively in their oral classroom interactions during Tigrinya sessions.

Furthermore, it was also noticed that most of the students use Amharic words like mäbt "right", hullättän̆ňa "second" etc, instead of the equivalent Tigrinya words mäsäl, xalPay in the paragraph they wrote.

The reason why these students make interferences of Amharic with Tigrinya could be due to the fact that the variety of Tigrinya spoken in Rayya in general and in Alamata in particular is highly influenced by Amharic. Regarding this, Moges (1993: 23) states that science Amharic is widely spoken by the people of the woreda in different socio-economic activities of the society, the Tigrinya variety spoken in this woreda is distorted by the influence of Amharic.

As a result of this, most of the people are observed by the researcher using Amharic in their daily communication. Since the students are also part of the whole society, they have been observed using a Tigrinya variety highly influenced by the interference.

\section{Conclusions}

Based on the investigations obtained above, the following findings have been arrived at in this study. Language is a critical means of access to all knowledge and skills, and it is a tool for all aspects of human civilization. Language and education are not separable. The role of a good command of instructional language in an instructional process is, therefore, very crucial due to the fact that it represents learners' theory of reality; it explains, interprets, constructs and reflects the linguistic and social identity of children in an early school setting. It also enables the learners to develop and reflect their self-esteem, intellectual, social and psychological being. The finding in this study, however, pointed out that most of the students are deprived of use of the appropriate linguistic tool for this. Many are not provided with the opportunity to reflect their real life and aspirations in the classroom interactions. This was not made possible due to the reason that there is a mismatch between the home language of the students in which they can express themselves and the language as well as the content they find in the actual classroom. It has been also confirmed that the dialectal variations between the Raya dialect and the MOI as well as the close contact between Tigrinya and Amharic have resulted in a negative impact in the classroom communication.

\section{Recommendations}

In this study, it has been found that there are some linguistic innovations which can be clearly noticed in the subject students' pronunciations. However, the possible reasons which have caused the students to innovate such linguistic aspects have not been discovered, yet. So, further study has to be conducted to investigate the possible historical causes.

Education officials at the regional, zonal and woreda levels and other concerned bodies should design different workshops and trainings for teachers as well as parental communities to discuss and make them aware of how the problems of the influence of Amharic on Tigrinya are serious to implement Tigrinya as language of instruction and to achieve successful educational objectives in Alamata Woreda primary schools.

Data in this study revealed that only Tigrinya teachers have been trying their best to solve the classroom language variation problems both individually and at the level of departments. Closing the gap between the home dialect (Raya Dialect) and the school language (MOI) reflected by these children, however, should not be the responsibility of the language teacher alone. That responsibility lies with every teacher and the whole school 
community. The researcher, therefore, strongly recommends that every teacher has to do his/her best to solve or to minimize the problems.

Some language teachers have been observed denying the home language of the students. However, these students should not be underestimated whenever they use their own variety because it is that variety which signifies the socio-economic, cultural norms as well as the linguistic background of the children's social group; both the teachers and the students should understand and appreciate the nature of language variation and language change. So the students have to be appreciated when they make unconscious interference of their own home dialect into the MOI in schools. They have to be persuaded that being able to know as many dialects or languages as they can know will benefit them to construct good social, political and economic affairs with people out of their social group.

Education officials and other concerned bodies should deal on the issue of classroom language problems in Alamata primary schools, and they have to design a new school-curriculum based on the interest, language ability and local situations of the students because learning will become meaningful if these learners are provided with the opportunity to bring their environmental, economic, social and cultural norms into their classroom lessons and then relate what they learn in the classroom with their real life activities.

\section{References}

Ager, Dennis E. (1996). Language Policy in Britain and France: The Process of Policy. London: Wellington House Press.

Amanuel Shale. (1988). 'Tigrinya: A Study in Standardization'. In International Congress of Ethiopian Studies. PP. 26-29. Moscow: Nauka Publisher.

Annamalai, E. (2003). Medium of Power: The Question of English in Education in India. In Tollefson, James W. and Tsui, Amy B. M. (Editors). Medium of Instruction Policies.Which Agenda? Whose Agenda? Mahwah, NJ: Lawrence Erlbaum, P. 177- 194.

Borg, W. R. and Gall, M. D. (1989). Educational Research. An Introduction (5th ed.). New York: Longman.

Brewer, J. and Hunter, A. (1989). Multi method Research: A Synthesis of Styles. Newbury Park, CA: Page.

Chernet Tekleweldeab. (1999). Parental Attitudes towards Children with Mental Retardation: The Case of Five Families in Nazareth Town, Ethiopia. Norway: University of Oslo. MA Thesis.

Daniel Mehari. (1991). 'The Origion and Development of Tigrinya Language'. In Teklehaymanot Haileslassie, Solomon Enquay, Muluwerq Kidanemariam and Mekonnen Mohamed. (Editors). mäs'naStitat K'äddamay Symposium tigriňn̆a. PP. 43-55. Addis Ababa: birhan ?inna sälam.

Daniel Teklu. (2000). 'hilwi kunätat sinnä-s'iłuf tigiriňňa'. In Gebreab Barnabas, Getahun Mesele, Gebregzabiher Bihon, Berhe Haile, Teklehaymanot Haileslassie and Solomon Enquay. (Editors). wis'ìit käyiddi mäbäl kalitay waSillan mäs'naSitin k'a $n k^{\prime w}$ atat tigiray. PP. 207-225. Mekelle: Planography Printing Press.

Fentahun Mengistu. (1999). 'Attitude of Teachers, Parents and Students towards Amharic Language as a

Meaza Birru. (1983). 'The Interference of Mother-Tongue in Second Language: A Case Study of Tigrinya Speakers'. Addis Ababa, Addis Ababa University: Unpublished. BA Thesis.

Moges Ali. (1993). 'lissanä-bizuhinnät Pinna yäk'k'wank'k'wa Pat't'äk'k'ak'k'äm bä Palamat't'a wäräda'. Addis Ababa, Addis Ababa University: Unpublished. BA Thesis.

Mohammed Siraj. (1983). 'Phonology of Rayan Dialect of Tigrinya'. Addis Ababa, Addis Ababa University: Unpublished. BA Thesis.

Patton, M. Q. (1987) How to Use Qualitative Methods in Evaluation. California: Sage Publications, Inc.

Smitherman, Geneva. (1998). 'African Americans, Ebonics and US Language Planning-Policy'. In Limage, Leslie. (Editor). Comparative Perspectives on Language and Literacy: Selected Papers from the Work of the Language and Literacy Commission of the $10^{\text {th }}$ World Congress of Comparative Education Societies. PP.5163. Cape Town: UNESCO-BREDA.

Spolsky, B. (1972). The Language Education of Minority Children: Selected Readings. USA: Newbury House Publishers, Inc.

Teklehaymanot Haileselassie. (2000). 'miłbalä k'awnk'wa tigriňňa Pab timhiriti'. In Gebreab Barnabas, Getahun Mesele, Gebregzabiher Bihon, Berhe Haile, Teklehaymanot Haileslassie and Solomon Enquay. (Editors).

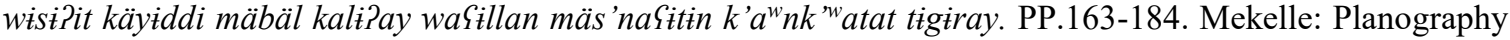
Printing Press.

Teshome Nekatibeb. (1998). Media Utilization and School Improvement: A Case Study of Primary Education Radio Support Program in Ethiopia. Stockholm University: Institute of Education. Dissertation.

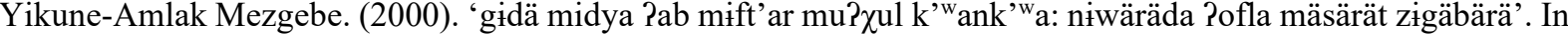
Gebreab Barnabas et al. (Editors). mäs'naStitat kal?ay Symposium Pab waSla k'wank'watat tigriňňa. Mekelle: Planography Printing press. 


\section{Acknowledgment}

I owe an immeasurable debt especially to Dr. Bekale Seyum and Dr. Ronny Meyer for their unreserved technical and professional guidance as well as time and effort they have devoted in the process realizing the study. My deepest and heartfelt admiration goes to my friends Dr. Muleta Yorga, Abraha Girmay, Bahre Araya, and Teklay Kahsay for their deep concern and devotion in carefully going through my draft manuscript and giving me useful suggestions. I am especially indebted to Abraha Girmay who sacrificed his time to comment Tigrinya translations and transcriptions. All words of appreciation are reserved to all friends of mine who, in one way or another, have contributed to the completion of this research. 